\title{
Crenças linguísticas de alunos do PROFLETRAS de universidades no Triângulo Mineiro
}

\section{Linguistic beliefs of PROFLETRAS students of universities in the Triângulo Mineiro (MG, Brazil)}

Talita de Cássia Marine ${ }^{1}$, Juliana Bertucci Barbosa²

Doutorado em Linguística e Língua Portuguesa pela UNESP/Araraquara com estágio PDEE/CAPES na Universidade de Lisboa. Professor Adjunto IV da Campus de Uberaba-MG . Professora Perronente Coordenadora Local do Mestrado Profissional em Letras (PROFLETRAS) da UFTM e na UNESP de Araraquara. Líder do Grupo de pesquisas GEVAR (Grupo de Estudos Variacionistas), plataforma CNPq. Coordenadora do PLI/CAPES (Programa de Licenciaturas Internacionais) na UFT

Doutorado em Linguística e Língua Portuguesa pela UNESP/Araraquara com estágio PDEE/ CAPES na Universidade de Lisboa. Professor Adjunto 3 da Universidade Federal de Uberlândia (UFU), Campus de Uberlândia-MG. Professora Permanente e Coordenadora Local do Mestrado Líder do Grupo de pesquisas GEVAR (Grupo de Estudos Variacionistas), plataforma CNPq. E-mail: talita.marine@gmail.com
RESUMO: Neste artigo, temos como objetivo geral investigar as crenças linguísticas de pós-graduandos do PROFLETRAS (professores da Educação Básica) de duas universidades federais do Triângulo Mineiro. Para atingirmos nosso objetivo, confeccionamos e aplicamos um questionário de crenças linguísticas destinadas aos participantes desta pesquisa. A análise de dados apontou, como resultado geral, o distanciamento do ensino de língua portuguesa na Educação Básica de uma atitude predominantemente reflexiva e de uma pedagogia culturalmente sensível às variações socioculturais e linguísticas. Somando os resultados de nossas investigações ao pressuposto de que o ensino de língua portuguesa no Brasil continua sendo praticado de modo ultrapassado e desconexo das orientações dos PCN, nossas pesquisas pretendem contribuir para o mapeamento das crenças linguísticas no Brasil e para a conscientização dos problemas que permeiam esta questão e dos obstáculos a serem enfrentados em prol de um ensino sociolinguístico de língua portuguesa.

PALAVRAS-CHAVE: Crença linguística; Ensino de língua portuguesa; Professores da Educação Básica; Profletras.

ABSTRACT: In this article we have as general purpose investigate linguistic beliefs graduate students of PROFLETRAS (basic education teachers) in two federal universities of the Triângulo Mineiro. To achieve our goal, we prepare and apply a linguistic beliefs questionnaire for participants of this survey. Data analysis pointed out, as a result, the General detachment of Portuguese language teaching in basic education of a predominantly reflective attitude and a culturally sensitive pedagogy, sociocultural and linguistic variations. Adding up the results of our investigations to the assumption that the teaching of Portuguese language in Brazil is still being practiced so outdated and scrappy of the guidelines of the PCN, our research aim to contribute to the mapping of language in Brazil and beliefs to the awareness of the problems that permeate this issue and obstacles to be faced for a sociolinguistic teaching of Portuguese language.

KEYwordS: Linguistic beliefs; Portuguese language teaching; Basic Education teachers; Profletras. 


\section{Introdução ${ }^{1}$}

perspectiva de língua adotada pelos Parâmetros Curriculares Nacionais

(doravante PCN) concebe-a como uma realidade dinâmica que se dá nas situações concretas de uso. Em consonância com tal postura e coadunando-nos com o que afirmam Martins, Vieira e Tavares (2014, p. 09), acreditamos que um dos maiores desafios do ensino de Língua Português no Brasil, sem dúvida, está relacionado "ao tratamento da variação linguística e, fundamentalmente, aos saberes gramaticais - permeados por diferentes normas linguísticas - que devem estar presentes na escola. (...). A multifacetada realidade brasileira, em todas as suas expressões socioculturais, reflete-se na produtiva e saudável convivência de diversas variedades linguísticas da vida escolar". Assim, buscamos, neste artigo $^{2}$, apresentar resultados de uma investigação sobre crenças linguísticas de pós-graduandos (professores da Educação Básica) do Mestrado Profissional em Letras (Profletras) de duas universidades federais da região do Triângulo Mineiro: Universidade Federal de Uberlândia (UFU) e Universidade Federal do Triângulo Mineiro (UFTM, campus de Uberaba).

Para atingirmos nossos objetivos, realizamos: (a) uma revisão teórica sobre o assunto, especialmente sobre os conceitos de crenças linguísticas, em estudos sociolinguísticos e em documentos do governo brasileiro; (b) a aplicação de um questionário de crenças linguísticas destinadas aos participantes desta pesquisa, (c) a análise de dados a partir do teste de crenças linguísticas aplicado.

Somando os resultados de nossas investigações ao pressuposto de que o ensino de língua portuguesa no Brasil continua sendo praticado de

\footnotetext{
Trabalho apresentado no Encontro do GT de Sociolinguística da ANPOLL / XXXI Encontro da ANPOLL (2016).
}

2 Agências de fomento: Capes e CNPq (Número do processo: 424520/2016-8). modo ultrapassado e desconexo das orientações dos PCN, nossas reflexões pretendem contribuir para a conscientização de problemas que realmente permeiam esta questão e de obstáculos a serem enfrentados em prol de um ensino sociolinguístico de língua portuguesa.

\section{Sociolinguística e ensino no Brasil: a busca por um ensino reflexivo}

Como tão bem ressaltou Camacho (2001, p. 49), apenas expor "que a Sociolinguística trata da relação entre língua e sociedade é fazer uma afirmação correta, mas, ao mesmo tempo, excessivamente simplificadora". Isso porque, nesta perspectiva teórica, "a relação entre língua e sociedade é encarada como indispensável, não mero recurso interdisciplinar" (CAMACHO, 2001, p. 50).

Posto isto, acreditamos que quando se propõe uma discussão acerca da interface da Sociolinguística com o ensino, no caso, o ensino de língua portuguesa no Brasil enquanto língua materna, seja de fundamental importância que se comprometa a falar de um ensino atrelado à reflexão acerca da realidade sociolinguística brasileira, o que significa considerar, de fato, as dimensões continentais desta Nação e que, por sua vez, acarretam diversas variações de ordem regional, socioeconômica e cultural. Variações que acabam identificando o Brasil como um país plurilíngue e multicultural, falante de uma variedade do português com características tão próprias que, já há algum tempo, a linguística moderna vem se referindo a ele como "Português Brasileiro", a fim de, justamente, marcar as peculiaridades desta variedade do Português que representam o uso que o falante brasileiro faz da língua portuguesa.

Orientações oficiais advindas de documentos de âmbito nacional (Parâmetros Curriculares Nacionais) destacam o (re)conhecimento da 
diversidade linguística no Brasil como um dos principais objetivos do ensino de língua portuguesa em nosso país, já que isso está diretamente ligado ao desenvolvimento da competência comunicativa dos alunos, uma vez que (re)conhecer e respeitar as variedades linguísticas, permite aos alunos a utilização da língua de maneira adequada - tanto na modalidade oral, quanto na escrita - em diferentes situações de interação. Entretanto, como bem ressaltam Martins, Vieira e Tavares (2014), essas orientações

ainda não se aplicam ao universo homogeneizador da língua escrita e ao que se tem chamado de língua ou norma padrão, relegando à variação e à diversidade - inerente a toda e qualquer norma linguística - o lugar do estereotipado e do socialmente marcado. Assim, perpetua-se o preconceito linguístico sob o mito de que existe uma única norma. Resulta, então, uma lastimável cultura de substituição da variedade do aluno, e não da desejável ampliação de seu repertório (MARTINS, VIEIRA e TAVARES, 2014, p. 07).

Nesse contexto, o cenário atual do ensino de língua portuguesa no Brasil mostra-se em um notório descompasso entre o que sugerem, por exemplo, os PCN (BRASIL, 1997; 1998) e o que se pratica em diversas salas de aula brasileiras, diariamente. A esse respeito, tal como ressalta Faraco (2011, p. 08):

Se, como resultado da intervenção dos lingüistas, o tema da variação acabou incorporado pelo discurso pedagógico, podemos dizer que não conseguimos ainda construir uma pedagogia adequada a essa área. Talvez porque não tenhamos ainda, como sociedade, discutido suficientemente, no espaço público, nossa heterogênea realidade lingüística, nem a violência simbólica que a atravessa.

Acreditamos também que para além das orientações sugeridas pelos documentos oficiais, temos grandes contribuições da Sociolinguística Educacional no sentido de enfatizar e legitimar cada vez mais a relevância de um ensino comprometido com a identidade do português brasileiro, ou seja, um português multifacetado que precisa ser assumido e respeitado nas nossas salas de aula à luz de uma culturally responsive pedagogy (ERICKSON, 1987, p. 355), ou seja, de uma "pedagogia culturalmente sensível", tal como sugerem, por exemplo, Bortoni-Ricardo e Dettoni (2001).

Segundo Erickson, uma culturally responsive pedagogy pode ser caracterizada por

um tipo de esforço especial empreendido pela escola capaz de reduzir a dificuldade de comunicação entre professores e alunos, desenvolver a confiança e prevenir a gênese de conflitos que rapidamente ultrapassam a dificuldade comunicativa, transformando-se em amargas lutas de identidade negativa entre alguns alunos e professores (ERICKSON, 1987, p. 355, tradução nossa).

Como podemos observar, a discussão entre Sociolinguística e Ensino é uma discussão emblemática, que envolve questões diversas. Todavia, tal discussão não pode ser mais preterida das conversas entre professores e futuros professores de língua portuguesa ou limitada ao âmbito acadêmico; ela precisa chegar às salas de aula mediadas pelo professor do Ensino Fundamental e Médio. Professor este que deve estar consciente de seu objeto de ensino, isto é, o Português Brasileiro: um objeto vivo, elástico e dinâmico que é usado diariamente por seus falantes, o povo brasileiro, igualmente vivo, elástico e dinâmico. Se partirmos de tais considerações e entendendo que a coocorrência de variedades linguísticas em sala de aula não precisa ser conflitiva, mas, sim, algo a se somar na busca pelo desenvolvimento da competência comunicativa dos alunos, há de se buscar caminhos para se lidar com a variação linguística em sala de aula e, por extensão, fora dela também.

Para isso, e considerando o que Freire (2011) denominou como "pedagogia da libertação", precisamos dar voz a nossos alunos para que 
possamos abandonar métodos pautados em transferência de conhecimento para outros que sejam dialógicos, no sentido bakhtiniano do termo (BAKHTIN, 1997). Nossos alunos precisam ser considerados como sujeitos sociais, construídos historicamente, com particularidades culturais e, por vezes, com restrições orçamentárias que lhes impede o acesso a bens de cultura que, na sociedade contemporânea, está bastante atrelado a espaços de letramento. E não podemos ignorar o fato de que se costuma, ainda hoje, associar a norma culta - por vezes apre(e)ndida de maneira equivocada, desconsiderandose o continuum em que se constitui - à escrita, dicotomizando-a em relação à norma popular - também grosseiramente tratada como una -, frequentemente associada à fala. $\mathrm{E}$ a esses lapsos que ainda percorrem as salas de aula, soma-se o pseudoconhecimento estilístico ${ }^{3}$ que se incute nos alunos: a noção de "formalidade" vs. "informalidade". Assim, em pleno século XXI, o combo "norma culta - escrita - formalidade" vs. "norma popular - fala - informalidade" é difundido em aulas de língua portuguesa, contribuindo para a artificialidade desse ensino e para todos os revezes que acompanham tal artificialidade.

Para combater esse quadro insalubre que caracteriza o ensino de língua portuguesa no Brasil, acreditamos que um diálogo com a Sociolinguística seja uma alternativa lúcida frente às características de diversas ordens que identificam nosso país. Nesse sentido, em concordância com o que ressaltam Martins, Vieira e Tavares (2014), destacamos três grandes contribuições da Sociolinguística Variacionista, sobretudo em relação aos estudos desenvolvidos no Brasil em interface com o ensino de língua portuguesa e que julgamos essenciais a um ensino reflexivo de língua: 3 Estamos denominando como "pseudoconhecimento estilístico" um conhecimento superficial e/ou
equivocado da variação estilística, tal como proposta por Camacho (1988), que engloba as diferentes
manifestações estilísticas do falante diante de situações formais e informais. (i) definição apurada de conceitos básicos para o tratamento adequado de fenômenos variáveis;

(ii) reconhecimento da pluralidade de normas brasileiras, complexo tecido de variedades em convivência;

(iii) estabelecimento de diversas semelhanças entre o que se convencionou chamar 'norma culta' e 'norma popular', não obstante os estereótipos linguísticos (cf. LABOV, 1972) facilmente identificados pela maioria dos falantes (MARTINS, VIEIRA e TAVARES, 2014, p. 10).

Para além disso, julgamos relevante destacar as pesquisas acerca das crenças e atitudes linguísticas que têm sido desenvolvidas no Brasil, oriundas do diálogo da Sociolinguística com o Ensino no âmbito do que se convencionou chamar de Sociolinguística Educacional. Tais estudos têm contribuído bastante na descrição e na compreensão do que alunos e professores acreditam ser a língua portuguesa, o que e como deve ser ensinado nas aulas de língua portuguesa, o que alunos e professores pensam sobre seus conhecimentos linguísticos, qual a avaliação que fazem das variedades linguísticas dispostas no seio social, o que entendem por norma culta e norma popular, entre outros.

As respostas para tais questões têm possibilitado que dimensionemos a autoestima linguística de professores de língua portuguesa e de seus alunos, apontando-nos, assim, os possíveis equívocos atrelados ao ensino de língua portuguesa e que podem estar diretamente relacionados a uma baixa autoestima linguística desses professores e alunos. Por outro lado, tais pesquisas podem contribuir também para que, quando diante de professores e alunos que reconheçam e valorizem a sua própria variedade linguística (ou seja, tenham uma alta autoestima linguística), possamos enxergar com mais clareza os pontos pertinentes desse ensino que podem estar influenciando positivamente na construção dessa valorização linguística.

Na seção seguinte, nosso foco será justamente este: propor uma discussão introdutória acerca dos conceitos de crença e atitudes lin- 
guísticas, em estudos sociolinguísticos e em documentos do governo brasileiro.

\section{Crenças, atitudes e ensino de língua portuguesa}

Seguindo as reflexões feitas ao longo deste artigo, o conhecimento de dois conceitos mostra-se essencial e deve ser levado em consideração quando se pensa na realização de um ensino de língua portuguesa respaldado pela perspectiva sociolinguística de língua e de ensino, a saber: a noção de crença e atitude linguística.

Crença e atitude linguística estão de tal forma relacionadas que não podemos tratá-las separadamente, uma vez que a primeira influencia a segunda. Assim, a ideia que se articula entre tais conceitos é a de que aquilo em que se acredita repercute naquilo em que se fala/faz. Grosso modo, podemos afirmar que à crença linguística associa-se "a posição em que os professores e os alunos colocam os objetos (língua, linguagem, variação e aprendizagem linguística) dentro da dimensão avaliativa, posição essa que, em última instância, leva à atitude deles em relação a esses objetos" (CYRANKA, 2007, p. 25). Já a atitude linguística é um resultado de convicções que o aluno tem sobre a língua e outros elementos relacionados a ela, como o ensino e a variação.

Considerando essas concepções (de crença e atitude), é necessário, no entanto, destacar que embora a orientação dos PCN em relação ao ensino de Língua Portuguesa apresente, explicitamente, a defesa por um ensino pautado no uso, na interação e, por conseguinte, no fenômeno da variação linguística, na prática, ou seja, em sala de aula, tal como ressalta Bagno (2002), as milenares noções e prescrições da doutrina gramatical normativa continuam, tradicionalmente, ocupando seus lugares. E, ainda de acordo com o autor, tal crença parece se manter "intocável" devido à expectativa vigente na sociedade em geral, sobretudo entre os pais dos alunos, de que "a escola ensine 'português' (entenda-se: gramática normativa) exatamente do mesmo modo como eles, pais, aprenderam em sua época de escola” (BAGNO, 2002, p. 16).

Por outro lado, numa perspectiva moderna de ensino de língua portuguesa, a noção maniqueísta de certo e errado perdeu espaço para as noções de mais e menos adequado aos diversos contextos de uso.

A questão não é falar certo ou errado, mas saber qual forma de fala utilizar considerando as características do contexto de comunicação, ou seja, saber adequar o registro às diferentes situações comunicativas. É saber coordenar satisfatoriamente o que falar e como fazê-lo, considerando a quem e por que se diz determinada coisa. É saber, portanto, quais variedades e registros da língua oral são pertinentes em função da intenção comunicativa, do contexto e dos interlocutores a quem o texto se dirige. A questão não é de correção da forma, mas de sua adequação às circunstâncias de uso, ou seja, de utilização eficaz da linguagem: falar bem é falar adequadamente, é produzir o efeito pretendido (BRASIL, 1997, p. 26).

Acreditamos que essas considerações apontadas pelos PCN de língua portuguesa às práticas sociais de fala valem para o uso da escrita, uma vez que essa modalidade, mesmo possuindo regras ortográficas que visam homogeneizar diferenças de pronúncia decorrentes, sobretudo, de variações de caráter diatópico e diastrático, também varia estilisticamente de acordo com o gênero discursivo em que se realiza. Assim, a escola, ao privilegiar o ensino de língua portuguesa a partir da escrita, deveria contemplar a diversidade de realização desta modalidade de língua, compreendendo e fazendo compreender que:

1. a variação linguística não é um fenômeno exclusivo da fala;

2. a maioria dos gêneros discursivos trabalhados pela/na escola são realizados por meio da norma culta, porém é preciso compreender que a norma culta é composta por um conjunto de variedades cultas dispostas em um continuum de monitoramento estilístico, variável quanto ao grau de formalidade; 
3. nem todos os gêneros discursivos se realizam por meio da norma culta. Entretanto, isso não justifica o fato de serem preteridos das salas de aula, afinal, é função da escola, sim, abordar tais gêneros, sobretudo aqueles que se mostram mais presentes na vida de seus alunos.

Deste modo, assumir uma postura sociolinguística em sala de aula vai além de falar da existência da diversidade linguística; é preciso assumila nas práticas de ensino-aprendizado dentro das salas de aula. Nesse sentido, desenvolver atividades que contemplem variedades populares é fundamental para que os alunos compreendam realmente o fenômeno da variação linguística e, assim, se dissociem dos possíveis preconceitos linguísticos que se perpetuam na sociedade e que acabam sendo legitimados e reforçados dentro e fora do ambiente escolar.

Como bem destaca Alkmim (2001, p. 29),

na realidade objetiva da vida social, há sempre uma ordenação valorativa das variedades linguísticas em uso, que reflete a hierarquia dos grupos sociais. Isto é, em todas as comunidades existem variedades que são consideradas superiores e outras inferiores.

Em outras palavras, como já ressaltava Gnerre (1985, p. 04), “uma variedade linguística vale o que valem na sociedade os seus falantes, isto é, vale como reflexo do poder e da autoridade que eles têm nas relações econômicas e sociais". Esses valores, socialmente construídos, fortalecem a difusão de crenças equivocadas atreladas às variedades linguísticas e acabam por determinar uma variedade como mais prestigiada do que outras; uma norma linguística "melhor" do que a outra e, aqui, leia-se: a norma culta vs. a norma popular.

A esse respeito, cabe destacar que, embora evidentemente heterogênea e distribuída em um continnum de monitoramento estilístico mais ou menos controlado pelo falante, visando adequação aos contextos de uso, a norma culta, como já afirmamos anteriormente, é enxergada pela sociedade como uma forma homogênea do "bem dizer" das elites letradas, enquanto a norma popular é representativa do falar despreocupado e desprestigiado do falante iletrado. E por isso, é tratada como reflexo de um uso "errado" da língua.

Assim, parece-nos evidente que as diferenças sociais e econômicas acabam determinando as regras do jogo de xadrez da vida em sociedade: as peças brancas, representantes das elites e falantes da norma culta, sempre têm, por direito, uma vantagem - arbitrariamente, sempre iniciam a partida -, em relação a seus oponentes, representados pelas peças pretas, isto é, o povo, falante, em sua imensa maioria, da dita norma popular.

Norma esta que a depender da variedade em que se materializa, carrega consigo um preconceito mais ou menos denso e, muitas vezes, socialmente legitimado, inclusive por seus próprios falantes que, crendo não saber o "verdadeiro português", sentem-se diminuídos na e pela sociedade que os cerca e os envolve e, por isso, a exclusão social, diretamente ligada à linguística, é simplesmente aceita como consequência de uma situação colocada como imutável. Nesse jogo de xadrez social, as peças brancas podem não vencer o jogo, mas sempre terão a vantagem de iniciar a partida. Afinal, regras são regras. Certo? Errado. Regras servem para serem questionadas, quebradas e redefinidas, sempre que necessário.

A oportunidade de iniciar a partida, que pode ser decisiva para apontar o vencedor do jogo, deve ser dada também às peças pretas. Metáforas à parte, o conhecimento da norma culta deve ser um direito de todos. Afinal, o aluno já chega à escola como um falante eficiente da sua língua materna que, a depender do ambiente em que vive(u), será marcada por variedades populares, cultas ou por variedades que representem uma mescla entre ambas.

A esse respeito, lê-se nos PCN: 
A Língua Portuguesa é uma unidade composta de muitas variedades. 0 aluno, ao entrar na escola, já sabe pelo menos uma dessas variedades: aquela que aprendeu pelo ato de estar inserido em uma comunidade de falantes. Certamente, ele é capaz de perceber que as formas da língua apresentam variação e que determinadas expressões ou modos de dizer podem ser apropriados para certas circunstâncias, mas não para outras (BRASIL, 1998, p. 80).

Dado o valor social que as variedades cultas possuem, contrariamente das populares, é dever da escola, enquanto instituição de ensino formal e responsável pela alfabetização do falante nativo, oportunizar aos seus alunos, durante todo o período escolar, o desenvolvimento do grau de letramento e da competência comunicativa, proporcionando-lhes o conhecimento da norma culta, bem como o re(conhecimento) da norma popular.

Considerando, de acordo com Faraco (2008, p. 42, grifo nosso), que norma "é o termo que usamos, nos estudos linguísticos, para designar os fatos da língua usuais, comuns, correntes numa determinada comunidade de fala" e que "uma norma, qualquer que seja, não pode ser compreendida apenas como um conjunto de formas linguísticas; ela é também (e principalmente) um agregado de valores socioculturais articulados com aquelas formas" (FARACO, 2008, p. 42, grifo nosso), um dos maiores desafios enfrentados diariamente pelos professores de língua portuguesa no Brasil, nos níveis fundamental e médio é, segundo Martins, Vieira e Tavares (2014), saber qual saberes gramaticais devem ser efetivamente acionados na escola.

Segundo tais autores,

é comum confundir o ensino de português com ensino de uma norma padrão homogeneizadora e abstrata, que em nada se aproxima dos diferentes usos efetivos da língua nas mais variadas situações de expressão sociocultural no país. Isso leva a dois grandes problemas, correlacionados entre si, que em muito têm prejudicado o ensino de português como língua materna: o preconceito linguístico e a falta de orientação quanto à multifacetada diversidade linguística brasileira a ser considerada em sala de aula (MARTINS, VIEIRA e TAVARES, 2014, p. 7).

Para além disso, assim como Travaglia (1997) e Cyranka (2015), concordamos que

criticar o 'ensino' tradicional de língua portuguesa significa negar a prevalência do ensino descritivo e prescritivo da gramática em favor do ensino reflexivo e produtivo (TRAVAGLIA, 1997). Significa, principalmente, utilizar a reflexão gramatical como ferramenta para o desenvolvimento da competência comunicativa, isto é, formar o leitor/produtor de texto maduro, crítico, autônomo. Mas significa também conhecer o aluno, saber a que comunidade de fala ele pertence, que valores culturais perpassam suas experiências, que práticas de letramento tem vivenciado, significa ter em mãos dados etnográficos que possam iluminar o caminho a ser percorrido (CYRANKA, 2015, p. 33).

Assim, é fundamental que docentes e futuros docentes de língua portuguesa estejam conscientes de: a) qual a concepção de língua embasa(rá) suas aulas; b) como desempenham ou desempenharão a sua prática docente; c) que tipo de ensino almejam desenvolver em suas aulas; d) quais são os objetivos a serem alcançados por meio de suas aulas. E, sobretudo, precisam: e) (re)conhecer que "a língua não pré-existe; ela se dá emergencialmente nas situações concretas de uso" (MARCUSCHI, 2007, p. 96) e, por fim, f) compreender que não existe uma única forma "certa" de falar e escrever.

Em relação a isso, já nos PCN, propostos em meados da década de 1990, ressaltava-se que

para poder ensinar Língua Portuguesa, a escola precisa livrar-se de alguns mitos: o de que existe uma única forma 'certa' de falar - a que se parece com a escrita - e o de que a escrita é o espelho da fala - e, sendo assim, seria preciso 'consertar' a fala do aluno para evitar que ele escreva errado' (BRASIL, 1997, p. 26). 
Ainda nesses documentos, lê-se que crenças como essas,

produziram uma prática de mutilação cultural que, além de desvalorizar a forma de falar do aluno, tratando sua comunidade como se fosse formada por incapazes, denota desconhecimento de que a escrita de uma língua não corresponde inteiramente a nenhum de seus dialetos, por mais prestígio que um deles tenha em um dado momento histórico (BRASIL, 1997, 26).

Apesar de se reconhecer a legitimidade dos PCN, respaldado por conhecimentos linguísticos modernos, sabemos que na prática, estamos muito distantes de um ensino predominantemente reflexivo e envolto por uma pedagogia culturalmente sensível (FARACO, 2011). O que de fato tem caracterizado o ensino de língua portuguesa no Brasil é um fracasso escolar relacionado, sobretudo, a um baixo desenvolvimento da competência comunicativa dos alunos brasileiros que se agiganta dia após dia entre nós, tal como podemos observar, entre outros, pelos resultados em pesquisas governamentais, como o Programa Internacional de Avaliação de Estudantes (PISA), desenvolvida pela Organização para a Cooperação e Desenvolvimento Econômico (OCDE) e o Sistema de Avaliação da Educação Básica (SAEB), desenvolvida pelo Instituto Nacional de Estudos e Pesquisas Educacionais Anísio Teixeira (INEP).

Nesse contexto, sem a pretensão de apontar heróis ou vilões, acreditamos, assim como Cyranka (2015), insufladas pelas reflexões de Paulo Freire (2011), que

cabe ao professor reconhecer, na linguagem, esse instrumento de libertação e ampliar as competências linguísticas dos alunos, a partir daquelas com que eles chegam à escola, sem negá-las, mas reconhecendo nelas importante aquisição já consolidada. Isso constitui uma decisão fundamental (CYRANKA, 2015, p. 34).

Por fim, cabe destacar que o ensino sociolinguístico que defendemos, a ser desenvolvido e praticado em nosso país, enxerga no (re)conhecimento e no estudo da diversidade sociolinguística do português brasileiro, um papel fundamental na formação da consciência linguística do falante e no desenvolvimento da competência comunicativa de nosso alunos, "devendo estar sistematicamente presente nas atividades de Língua Portuguesa" (BRASIL, 1998, p. 82) e não como conteúdo superficial, caricato e, por vezes, equivocado da variação linguística, abordado em uma ou duas aulas do ano letivo.

\section{Dos porquês de não termos um ensino reflexivo e uma prática da pedagogia culturalmente sensível}

Levando-se em consideração as reflexões promovidas nas seções anteriores deste artigo, parece-nos que, mesmo prevendo que os obstáculos serão muitos, o caminho a ser seguido rumo a um ensino reflexivo da língua, respaldado por uma prática pedagógica culturalmente sensível, já está traçado. Assim como Cyranka (2015, p. 33), acreditamos que, enfim, "os tempos da sociolinguística educacional são chegados".

Há uma crença social muito forte presente em diversas instâncias da sociedade, especialmente na escola e na família, a respeito do que significa o ensino de Língua Portuguesa, orientada por um viés ideológico elitista e conservador que acaba por contribuir para a manutenção de um ensino tradicional pautado na dita "norma-padrão", centrado na escrita e que despreza e/ou desvaloriza toda e qualquer realização linguística que não se enquadre nas prescrições e proscrições da língua consideradas como "corretas", "bonitas" e "elegantes".

Os equívocos desta postura são vários, mas deles destacamos o fato de se confundir o compromisso da escola com o ensino da norma culta - e que a nosso ver, deve se pautar por uma perspectiva sociolinguística de língua e ensino -, com um ensino da norma-padrão. Tal norma, de acordo com Bagno 
(2007), é de um "construto sócio-histórico" que serve de referência para estimular um processo de uniformização.

Nesse sentido, para Faraco (2008, p. 75), “a norma-padrão é uma codificação relativamente abstrata, uma baliza extraída do uso real para servir de referência". Portanto, não podemos tratar como sinônimas a norma culta e a norma-padrão, tampouco julgar que é papel da escola ensinar a norma padrão, afinal podemos dizer que tal norma é abstrata e "singular"; é idealizada e, portanto, não corresponde à língua em uso. Diferentemente da norma culta, que podemos concebê-la como concreta e "plural", correspondente à língua em uso em situações de maior monitoramento da fala e da escrita e que é constituída por variedades cultas da língua.

A confusão conceitual perpassa as divergências teóricas e atinge a realidade da sala de aula, fazendo com que o aluno enxergue a própria língua como algo de difícil apreensão, inatingível e por isso mesmo, seu estudo acaba se tornando monótono, descontextualizado e impositivo.

Acreditamos que parte dessa realidade é reflexo de uma formação com lacunas dos licenciados em língua portuguesa que, quando entram em sala de aula, acabam enfrentando dificuldades severas ao tentarem colocar em prática, a teoria a que tiveram acesso em sua formação. E isso, por sua vez, está atrelado a motivos diversos: os recém-professores não conseguem estabelecer uma conexão entre a teoria linguística estudada durante a graduação e a prática a ser estabelecida nas salas de aula ou, quando conseguem, tanto em função da resistência à mudança por parte das escolas, quanto dos pais dos alunos - ainda muitos resistentes à mudança na forma de se realizar o ensino de Língua Portuguesa -, acabam sendo confrontados e desestimulados a lançarem mão de uma prática pedagógica avessa ao modelo tradicional.

Por outro lado, temos também outra realidade: professores de língua portuguesa que se formaram há alguns (ou muitos) anos e não tiveram acesso à discussão de questões atreladas à variação linguística e ao ensino pautado nos gêneros discursivos, já que tais temas sequer faziam parte da grade curricular de sua formação e, por isso, esses professores desconhecem abordagens, metodologias, teorias e práticas mais contemporâneas a serem implantadas nas salas de aula. Com isso, ficam engessados em um modelo de ensino tradicional, norteado pela prescrição da norma culta, indiferente à heterogeneidade da língua e que há anos tem se mostrado ineficiente ao desenvolvimento da competência comunicativa dos alunos.

Fica evidente que este cenário precisa ser modificado em prol de um ensino de língua mais moderno, democrático, crítico e reflexivo, norteado por uma perspectiva sociolinguística de língua e pela pedagogia culturalmente sensível. Para isso, precisamos olhar com mais atenção para a formação linguística, em interface com o ensino, que temos dado aos profissionais da língua portuguesa, tanto nos cursos de graduação, quanto nos cursos de pós-graduação.

Acreditando nisso, neste artigo, apresentamos algumas considerações e reflexões acerca das crenças linguísticas de professores da Educação Básica da Rede Pública de Ensino que são alunos do Mestrado Profissional em Letras (Profletras), um curso de pós-graduação stricto sensu voltado especificamente para a formação do professor de língua portuguesa e para as práticas desenvolvidas em sala de aula no Ensino Fundamental.

\section{Descrição dos procedimentos metodológicos}

Para a realização deste estudo, inicialmente aprovamos o projeto no Comitê de Ética em Pesquisa, via Plataforma Brasil, número do parecer de aprovação 1.575.093, bem como os subprojetos de duas mestrandas, cujos números dos pareceres de aprovação são 1.416 .600 e 
1.414.6074 . Como instrumento de pesquisa, elaboramos um teste de crenças linguísticas ${ }^{5}$ que foi aplicado a professores de Língua Portuguesa da Educação Básica e que são alunos do Mestrado Profissional em Letras ${ }^{6}$ (Profletras) de duas universidades federais da região do Triângulo Mineiro: Universidade Federal de Uberlândia (UFU) e Universidade Federal do Triângulo Mineiro (UFTM), campus de Uberaba.

Tal teste foi dividido em duas partes para que pudéssemos conhecer melhor o universo dos professores. A primeira parte buscou coletar informações como gênero, idade, local de trabalho, formação acadêmica, tempo de formado, tempo de exercício de magistério, entre outros. A segunda, com 23 questões fechadas, procurou conhecer as crenças dos professores referentes à língua, à escrita e à fala.

Além das respostas fechadas (geralmente, "sim" ou "não"), deixamos um espaço para que os professores pudessem acrescentar comentários sobre a sua resposta, se assim desejassem. Tal como Cyranka (2007), evitamos elaborar questões negativas para não ocasionar ambiguidades, situação comum quando há a presença de duas negações (da pergunta e da resposta).

Os dados desse teste foram analisados quantitativamente com auxílio do Excel, aplicativo Windows, que fornece ferramentas para organizar, analisar e interpretar dados. Das quatro funções principais deste aplicativo, as utilizadas foram planilhas (com o uso de fórmulas), banco de dados e gráficos. Inicialmente, os dados foram analisados separadamente: por

${ }_{4}$ Tais projetos de pesquisa foram desenvolvidos pelas mestrandas Carla Beatriz Frasson e Romilda Ferreira Santos Vieira, orientadas pela Profa. Dra. Talita de Cássia Marine, no âmbito do Curso de Mestrado Profissional em Letras (PROFLETRAS) da Universidade Federal de Uberlândia.

5 Teste de crença baseado em Cyranka (2007) e nos testes propostos nas dissertações defendidas pelas mestrandas referidas na nota 6 deste artigo.

${ }^{6}$ Cabe observar que são alunos ingressantes no final de 2015, no Profletras-UFU e início de 2016, no Profletras-UFTM. Em ambas universidades, o teste foi aplicado nas primeiras semanas de aula do semestre letivo de 2016 universidade, por região, por escolaridade. Posteriormente, como os resultados encontrados separadamente, em sua maioria, eram aproximados, relacionamos e juntamos as informações.

Após essas tabulações dos dados extraídos do questionário, realizamos a análise exploratória, selecionando os componentes principais que poderiam representar o perfil e as crenças linguísticas dos mestrandos do Profletras da região do Triângulo Mineiro.

Cabe mencionar ainda que, como o questionário possibilitava aos participantes da pesquisa a inserção de comentários sobre as suas escolhas de respostas (fechadas), também realizamos a análise de conteúdo (MINAYO, 2007) das afirmações dos professores, buscando interpretar suas percepções sobre a língua, a escrita e a fala, ou seja, interpretando suas manifestações sobre o nosso objeto de estudo. Segundo Cavalcanti et al. (2008), a abordagem qualitativa aplica-se ao estudo da história, das relações, das representações, das crenças, das percepções e das opiniões, produto das interpretações que os indivíduos fazem de como vivem, constroem suas crenças e a si mesmos, sentem e pensam. Assim, neste trabalho, a análise de conteúdo foi utilizada para o aprofundamento de estudos quantitativos.

\section{Análise do teste de crenças}

A seguir, apresentamos os resultados da aplicação do teste de crenças aos alunos do Profletras das duas universidades federais da região do Triângulo Mineiro: Universidade Federal de Uberlândia (UFU) e Universidade Federal do Triângulo Mineiro (UFTM-Uberaba). Cabe ressaltar que, mesmo tendo verificado que em todas as respostas há indícios - ora maiores, ora menores - das crenças linguísticas dos participantes da pesquisa, descreveremos e discutiremos, neste artigo, apenas parte dos resultados observados. Nosso critério de seleção levou em conta as repostas que se mostraram mais 
contundentes no que se referia às concepções de língua, de fala, de escrita, de variação linguística e de atividades docentes encontradas a partir da aplicação do teste.

\subsection{Resultados do perfil social}

Ao aplicarmos o teste nas duas universidades, obtivemos 14 respondentes ${ }^{7}$ de cada instituição, totalizando 28 participantes da pesquisa. Inicialmente, nossa intenção era selecionar para aplicação dos testes apenas professores do Profletras da UFTM e da UFU que atuassem e fossem naturais de cidades da região do Triângulo Mineiro. Entretanto, ao fazermos um levantamento dos mestrandos do Profletras dessas duas universidades federais, verificamos que os alunos eram de regiões distintas. Por isso, o foco da nossa análise passou a ser alunos do Profletras "de duas unidades do Triângulo Mineiro" e não mais "da região do Triângulo Mineiro".

Assim, após aplicarmos o teste, observamos que o Profletras da UFTM possui alunos oriundos de Uberaba, de cidades da região do Triângulo Mineiro, do sul de Minas Gerais e do oeste do estado de São Paulo. Já o Profletras da UFU possui alunos de Uberlândia, de cidades da região do Triângulo Mineiro, de Brasília (cidades satélites) e de cidades do interior de Goiás.

Essa primeira parte do teste ainda demonstrou que tais professores:

a) estão na faixa etária de 25 a 45 anos;

b) são, predominantemente, do gênero feminino (71\% do gênero feminino e $29 \%$ do gênero masculino);

\footnotetext{
7 A turma do Profletras-UFU utilizada para os fins desta pesquisa é composta por 15 alunos. Ao serem solicitados para responderem ao teste, todos fizeram questão de participar da pesquisa. A única aluna que não respondeu ao teste não estava presente no dia da aplicação. Na UFTM, a turma pesquisada composta por 16 alunos e, assim como os discentes da UFU, a maioria deles mostrou-se bastante receptiva a responderem ao teste, apenas um não quis responder e outro preencheu o teste pela
metade, alegando não estar confortável para continuar.
}

c) cursaram, $75 \%$ deles, o Curso de Letras em universidades/faculdades particulares;

d) graduaram-se em Letras no final dos anos de 1990 ou na primeira década de 2000, formando-se, portanto, depois da publicação dos PCN e de muitas pesquisas científicas relacionadas aos problemas do ensino de língua portuguesa;

e) $82 \%$ fizeram curso de pós-graduação lato sensu (geralmente, na área de ensino/metodologia de Língua Portuguesa ou supervisão de ensino), os demais cursaram somente graduação.

Em relação ao tempo de exercício de magistério, apresentamos na Tabela 1 os resultados diferentes entre as duas universidades.

Tabela 1 - Tempo de magistérios dos professores da Educação Básica

\begin{tabular}{lcc}
\hline Tempo de magistério & UFU & UFTM \\
até 10 anos & $21 \%$ & $71 \%$ \\
de 11 a 20 anos & $58 \%$ & $29 \%$ \\
mais de 21 anos & $21 \%$ & - \\
\hline
\end{tabular}

Como podemos observar, os mestrandos da UFTM possuem uma experiência menor em sala de aula $(71 \%$ tem tempo de magistério de "até 10 anos"), embora nas duas universidades os alunos tenham se graduado aproximadamente na mesma época. Esse resultado pode ser relacionado à informação "fez outra graduação além de Letras?", em que verificamos que os alunos do Profletras da UFTM, em sua maioria, fizeram outros cursos superiores (58\%), já os da UFU, predominantemente graduaram-se em Letras (92\%). Esse segundo resultado (com base na pergunta sobre outro curso superior), pode justificar o menor tempo de magistério dos alunos da UFTM-Uberaba 


\subsection{As crenças linguísticas dos mestrandos do Profletras da região do Triângulo Mineiro}

Ao computarmos e procedermos às análises dos resultados obtidos pela aplicação do teste de crenças linguísticas entre professores de Língua Portuguesa da Educação Básica - alunos do Profletras das unidades da região do Triângulo Mineiro - pudemos observar, claramente, as relações que estabelecem com a escrita e a fala. Entre os resultados obtidos, representamos, no Gráfico 1, por exemplo, aqueles referentes às questões "1. Você escreve bem?" e "2. Você fala bem?":

Gráfico 1 - Respostas das questões 1 e 2 do teste de crenças

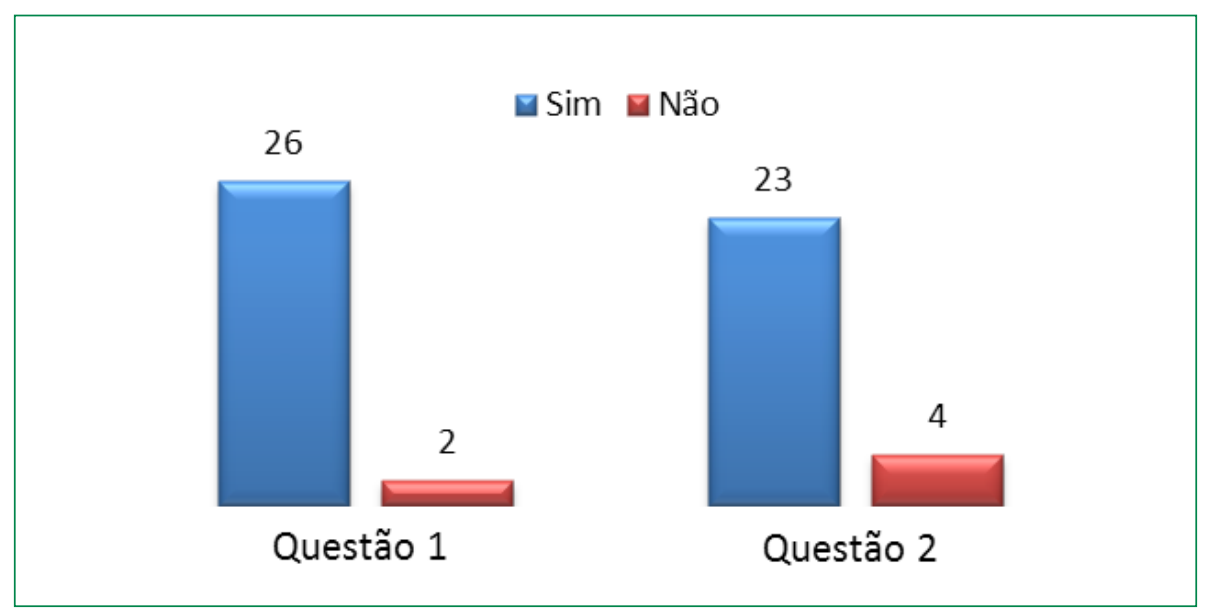

Como podemos observar, os professores, ao serem questionados sobre a sua própria escrita e fala, acreditam, em sua maioria, (26/93\% para escrita e 23/82\% para fala) que "falam" e "escrevem" bem, ou seja, estão seguros de que dominam tais habilidades. Entretanto, alguns deles, embora tenham assinalado "sim" como resposta, complementaram sua resposta com comentários, tais como:

Fragmento 01: “'Achava' que escrevia bem, até iniciar o PROFLETRAS.” (I05U)

Fragmento 02: “depende do gênero." (I10U)

Fragmento 03: "eu escrevo melhor do que falo." (I04T)

Comentários como os do Fragmento 01 acabam soando de modo paradoxal à resposta dada anteriormente, afinal, em um primeiro momento, o aluno declara escrever bem, mas depois reavalia a própria afirmação, ponderando: “Achava que escrevia bem, até iniciar o Profletras".

Já no Fragmento 02, ao condicionar “o falar e o escrever bem” ao gênero discursivo utilizado, acreditamos que tal comentário seja positivo, podendo apontar para uma formação linguística mais moderna desse professor, consciente das diferentes realizações estilísticas da língua em aderência ao gênero no qual se materializa.

Em relação ao Fragmento 03, o que nos chamou a atenção é o fato de o professor de português, ao julgar que sabe escrever melhor do que falar, denuncia, provavelmente, o reflexo de algo que deve ser transformado dentro do ambiente escolar: a supremacia da escrita em relação à fala, preterindo o ensino sistematizado da fala, das características da oralidade, em prol de um ensino pautado exclusivamente ou quase exclusivamente pela escrita. Se o próprio professor de língua portuguesa não se julga tão hábil no uso da fala, quanto se julga no da escrita, imaginemos: qual a relação que os alunos do Ensino Fundamental possuem com os gêneros orais? Tal reflexão apenas reforça o fato de que acreditamos que os alunos da Escola Básica precisam ter condições de utilizarem também, com segurança e em diferentes situações comunicativas, os gêneros discursivos 
orais. E para isso, seus professores devem estar aptos para atenderem a essa demanda.

Já entre as avaliações negativas, as duas respostas computadas em relação à escrita apresentaram o seguinte comentário:

Fragmento 04: "Ainda estou longe do que almejo/desejo." (I13U/I09T)

Essa ponderação pode estar associada à crença ainda presente nas aulas de língua portuguesa de que a escrita é mais complexa (ou "difícil”) e mais formal do que a fala. Sobre essa falsa crença, Marcuschi $(2007$, p. 37) já chamava a atenção para o fato de que a

fala tem sido vista na perspectiva da escrita e num quadro de dicotomias estritas porque predominou o paradigma teórico da análise imanente ao código. Enquanto a escrita foi tomada pela maioria dos estudiosos como estruturalmente elaborada, complexa, formal e abstrata, a fala era tida como concreta, contextual e estruturalmente simples.

Ainda sobre as modalidades "falada" e "escrita" da língua, fizemos outros questionamentos, tal como exemplificados pelas questões "3. Para você, qual modalidade de língua é mais correta?" e "5. Para você, qual modalidade de língua é mais difícil?". Como possibilidades de resposta, o teste apresentava "A língua escrita" ou "A língua falada", entretanto, cerca de 64\% dos alunos do Profletras (18 dos 28) assinalaram as duas alternativas ou deixaram-nas em branco, acrescentando ao espaço destinado a possíveis comentários, duas outras possibilidades de resposta: (01) "não existe modalidade melhor" (ou "ambas estão corretas") ou (02) condicionaram a resposta ao contexto, mencionando que "depende do contexto, uma pode ser melhor do que a outra". Por isso, tabulamos os dados, organizados no Gráfico 2, considerando quatro respostas possíveis.
Gráfico 2 - Respostas das questões 3 e 5 do teste de crenças

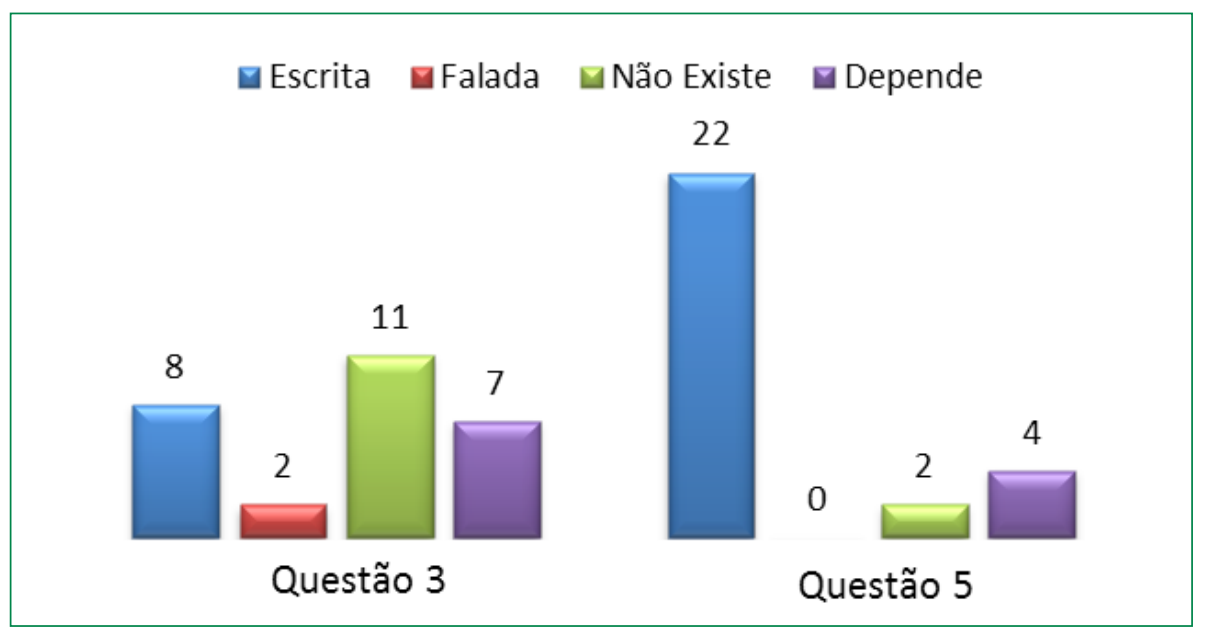

Em relação à questão 3, observamos que 39\% (11 respostas) dos professores, demonstraram reconhecer a relação "fala" e "escrita", ao afirmarem que não existe uma modalidade mais correta que a outra. No entanto, 28,5\% (08 respostas) responderam que a escrita é "mais correta" que a fala, apenas 7\% (02 respostas) afirmaram o contrário e 25\% (07 respostas) condicionaram o status de maior correção ao "contexto". A partir desses dados, podemos inferir que a maioria deles ainda acredita que uma modalidade é melhor do que a outra e/ou que o contexto pode definir isso.

Esse resultado pode ser correlacionado aos da questão 5 do teste ("Para você, qual modalidade da língua é mais difícil?”), em que $93 \%{ }^{8}$ acreditam que a modalidade escrita é mais difícil que a modalidade falada e nenhum deles afirmou que a fala é mais difícil que a escrita, embora em questões

8 Esses 93\% correspondem à porcentagem da soma: 22 casos que indicaram que a escrita é mais difíci e 04 casos que mencionaram o contexto como elemento definidor. Assim temos: $22+4=26$ respostas correspondendo aos $93 \%$ mencionados. 
anteriores, já apresentadas no Gráfico 1, alguns alunos tenham afirmado que julgam escrever melhor do que falar. Tais constatações demonstram que a relação de continuum entre "fala" e "escrita" apontada por Marcuschi (2007) ainda não é um conceito (re)conhecido por muitos professores de língua portuguesa9.

Outras questões do teste buscaram avaliar as crenças dos professores ligadas à sua prática em sala de aula. Entre os resultados, destacamos as respostas dadas à pergunta 9: "Há diferença entre a língua que você fala e a língua ensinada nas aulas de língua portuguesa?". Vejamos os resultados:

Gráfico 3 - Resposta da questão 9 do teste de crenças

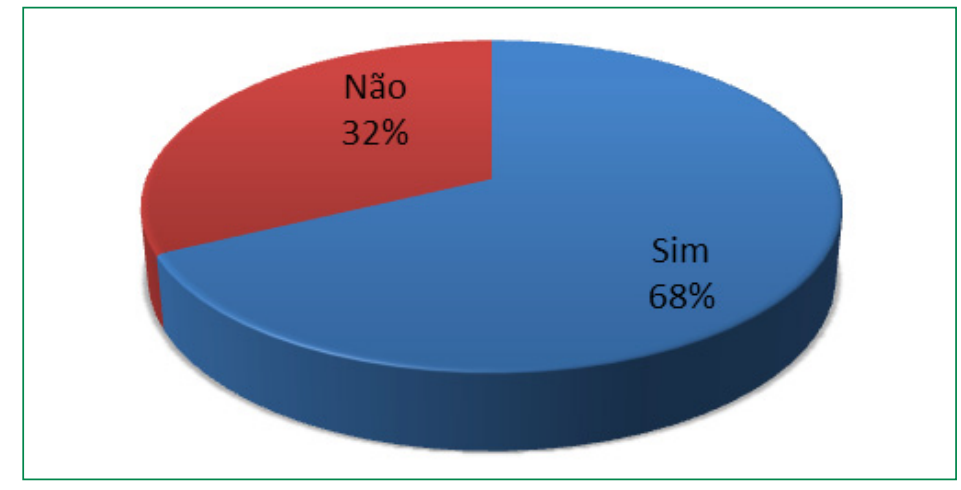

O Gráfico 3 evidencia que embora $68 \%$ dos professores tenham respondido "sim", ou seja, que acreditam existir diferenças entre a língua por eles falada no cotidiano e a língua ensinada nas aulas de língua portuguesa,

\footnotetext{
${ }_{9}$ Como menciona Almeida Baronas (2014, p. 48), "corroborando com as ideias de Marcuschi (2001), Bortoni-Ricardo (2004) apresenta uma proposta de contínuos de oralidade e escrita para os eventos comunicativos, havendo também pólos de maior predominância ou da oralidade ou da escrita. Cabe ressaltar a jă pode história da escrita na vida do ser humano".
}

$32 \%$ afirmam que a língua ensinada em sala de aula coincide com a empregada pelos usuários das línguas nos mais diversificados contextos de uso. Tais resultados nos despertaram para outros questionamentos: que variedade da língua é essa, mencionada por $32 \%$ dos professores, que coincide com aquela que ensinam em sala de aula? E mais: dentre os $68 \%$ dos professores que afirmaram existir diferenças entre a língua que falam e a língua que ensinam, quais variedades da língua são essas que compõem um e outro uso? Tais diferenças realmente existem ou são fruto de crenças coletivas (com)partilhadas no seio da sociedade e que dicotomizam a língua em dois grandes blocos: em um, a língua usada no cotidiano, em outro, a língua estudada na escola?

Outra questão do teste ligada à prática em sala de aula dos professores foi a de número 17: "Você compreende bem a linguagem utilizada no livro didático de língua portuguesa?". Como podemos verificar no Gráfico 4, nesta questão alguns professores não assinalaram as alternativas possíveis ("sim" ou "não"), porém, na parte destinada aos comentários, escreveram que "depende do contexto". Por isso, tabulamos os dados com três respostas possíveis:

Gráfico 4 - Resposta da questão 17 do teste de crenças

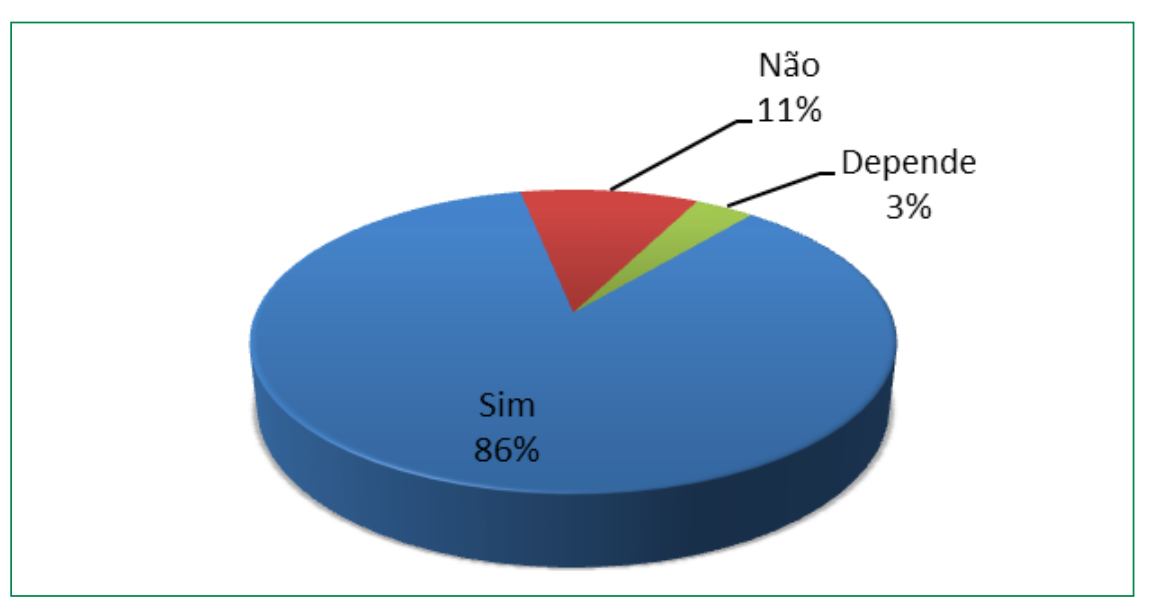


De acordo com os resultados apresentados no Gráfico 4, a grande maioria afirma compreender bem a linguagem utilizada no livro didático e apenas $11 \%$ afirmam o contrário. Entretanto, mesmo representando um percentual bastante baixo, $3 \%$, as respostas manifestadas com a expressão "depende do contexto", chamaram-nos a atenção para refletir acerca de que contexto é este mencionado pelos professores. Em relação a esse resultado (da questão 17), é importante destacar que nenhum professor descreveu, no espaço destinado aos comentários, possíveis dificuldade de entender o conteúdo do livro, problemas teóricos ou, ainda, fragilidades do conteúdo apresentado. Entretanto, como já demonstraram alguns autores, em suas pesquisas (tais como FARACO, 2011; ALMEIDA BARONAS, 2014, entre outros), os livros didáticos apresentam lacunas, não conseguindo promover um ensino reflexivo de língua e desconsiderando - ou considerando pouco - a heterogeneidade da língua.

Em outra parte do teste, por meio de questões como "19. Você tem orgulho da maneira como você fala?" e "21. Você gostaria de substituir o seu jeito de falar?", buscamos investigar as crenças dos professores em relação a sua própria variedade (Gráfico 5).

Gráfico 5 - Respostas das questões 19 e 21 do teste de crenças

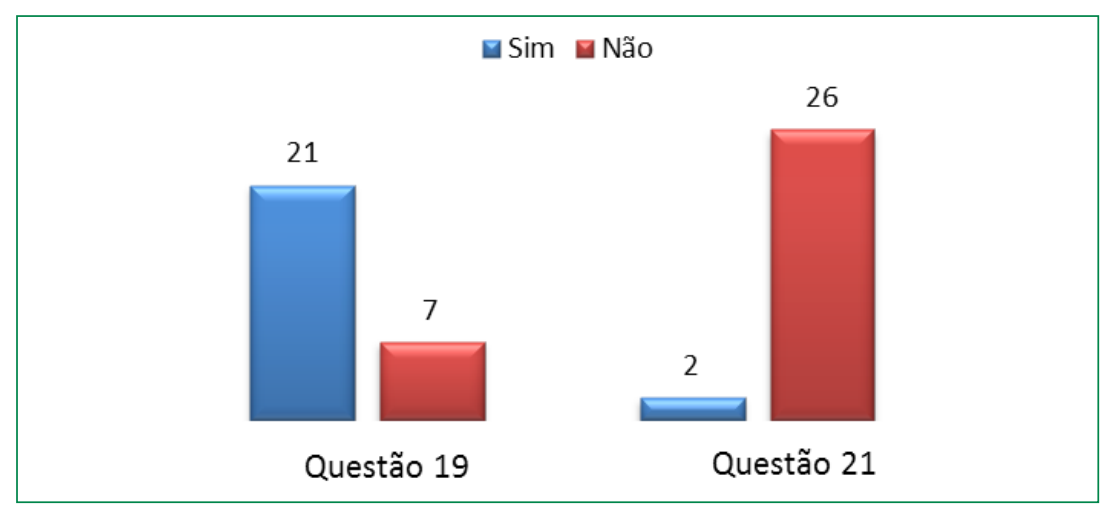

O Gráfico 5 demonstra que os professores aceitam suas variedades e não as estigmatizam. Inclusive não houve comentários, no espaço destinado a isso, em nenhuma das respostas a essas questões. Entretanto, apesar de avaliarem positivamente suas variedades, ao serem questionados sobre a avaliação dos outros em relação à variedade que falam, por meio da questão “20. Algum dia, você já se sentiu discriminado pelo seu jeito de falar?", verificamos um resultado diferente (Gráfico 6).

Gráfico 6 - Respostas da questão 20 do teste de crenças

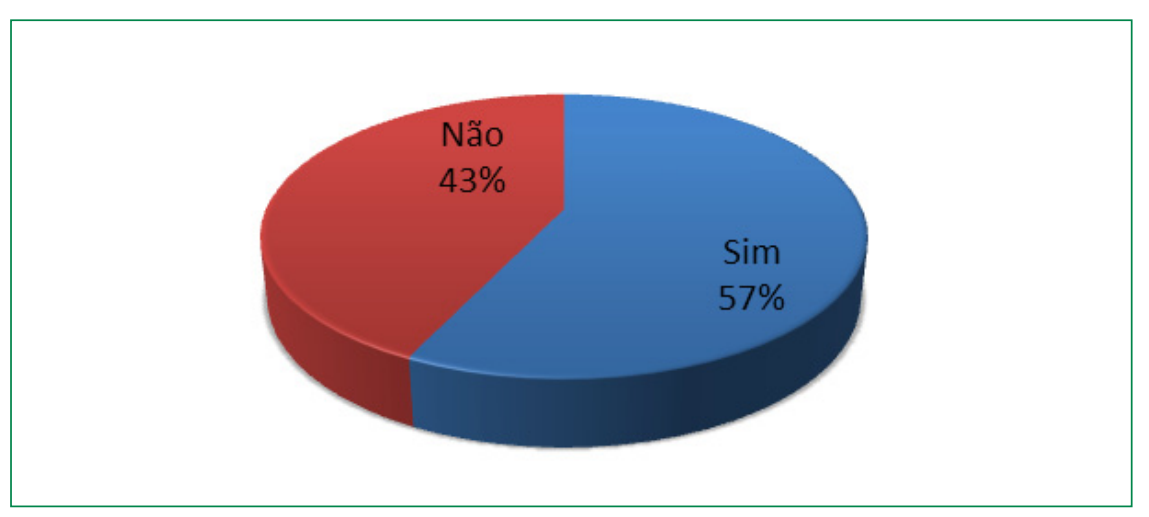

Como podemos observar, 57\% afirmaram já ter sofrido algum tipo de discriminação em relação à variedade linguística que falam. Acrescido a esta constatação, ainda destacaram:

Fragmento 05: "pelo fato de ser de cidade do interior." (I014U)

Fragmento 06: "quando fui para outros estados." (010T)

O resultado evidenciado no Gráfico 6 - somado às afirmações como as dos Fragmentos 05 e 06 - reforça ainda mais, como já destacamos nas 
seções anteriores deste artigo, a necessidade de as escolas, de os professores, principalmente nas aulas de língua portuguesa, adotarem uma prática pedagógica culturalmente sensível à variação linguística, promovendo um ensino reflexivo da língua, considerando sua diversidade e valorizando as diferenças. Por fim, outro resultado que consideramos relevante e positivo foi o obtido a partir da questão 22: "Você fala do mesmo jeito em diferentes contextos?". Vejamos o Gráfico 7:

Gráfico 7 - Respostas da questão 22 do teste de crenças

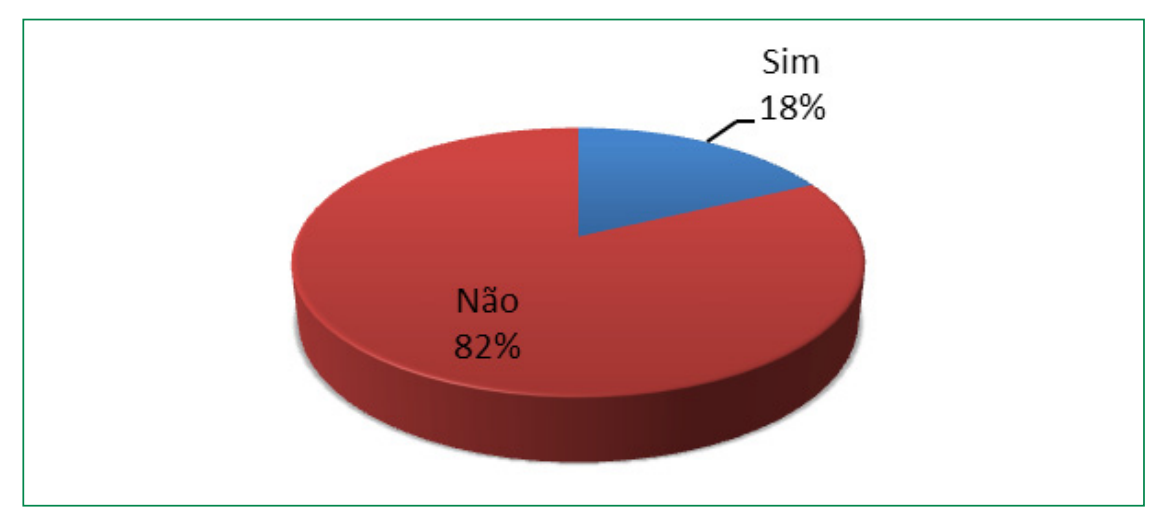

O Gráfico 7 pode, por um lado, apontar para o fato de que os professores de Língua Portuguesa, alunos do Profletras, parecem já compreender que não utilizamos as mesmas variedades da língua em todos os contextos; entendem que as diferentes práticas sociais em que estamos constantemente envolvidos podem condicionar diferentes usos da língua. Essa leitura pode confirmar nossa constatação, já mencionada no início da seção 4 deste artigo: o ensino reflexivo da língua, respaldado por uma prática pedagógica culturalmente sensível, "já está traçado" e começa a aparecer nas crenças de nossos professores. Por outro lado, esse dado também retoma a reflexão já realizada para a questão 9 ("Há diferença entre a língua que você fala e a língua ensinada nas aulas de língua portuguesa?"), pois os professores ao reconhecerem que não falam do mesmo jeito, em diferentes contextos, podem estar se referindo à crença dicotômica de que existem "duas línguas", a coloquial, usado no dia a dia, e a formal, empregada, por exemplo, na escola, no trabalho.

\section{Considerações finais}

Ao longo deste artigo, buscamos defender uma prática pedagógica sensível à variação linguística - já prevista, inclusive, em documentos federais, norteadores do ensino de língua portuguesa no Brasil -, que oportunize aos alunos a reflexão sobre a sua própria variedade da língua e leve-os ao desenvolvimento da competência comunicativa, possibilitando-lhes que consigam utilizar a modalidade oral e escrita da Língua Portuguesa, em diferentes situações e demandas de uso, de modo seguro, autônomo e eficiente.

Para isso, o professor precisa incluir em suas aulas, atividades contínuas que assegurem a reflexão acerca da heterogeneidade da língua, o (re)conhecimento da variedade brasileira do Português como legítima e representativa do falar do povo brasileiro, bem como propostas didáticas de intervenção que abordem de maneira reflexiva e sistematizada, diferentes gêneros discursivos da fala e da escrita, privilegiando com tais propostas, a visão de continuum entre essas duas modalidades da língua, a fim de combater o olhar dicotômico que geralmente se atribui à fala e à escrita.

Procuramos demonstrar também que, para que consigamos alcançar um ensino de língua portuguesa produtivo, envolto por uma perspectiva sociolinguística de língua e amparado por uma pedagogia culturalmente sensível, precisamos, primeiramente, traçar um perfil social dos professores 
que estão atuando nas salas de aula das escolas públicas brasileiras, bem como diagnosticar suas crenças a respeito de língua e do ensino de língua portuguesa. Isso porque acreditamos que uma melhoria qualitativa do ensino de língua portuguesa no Brasil só se dará quando a Educação do país olhar para as lacunas de formação de seus docentes, com o propósito de buscar caminhos e alternativas que visem sanar ou minimizar tais deficiências.

Nesse sentido, vislumbramos no Profletras - Curso de Mestrado Profissional em Letras - um desses caminhos, uma dessas alternativas que podem, de fato, sanar ou, ao menos, minimizar as deficiências de formação de centenas de professores de língua portuguesa, Brasil afora. Afinal, tal curso é oferecido em rede nacional desde 2013, abarcando, atualmente, 42 instituições de ensino superior, nas cinco regiões brasileiras. Identificar, refletir e compreender as crenças linguísticas desse corpo ambivalente - já que ao mesmo tempo que são alunos (pós-graduandos), são também professores regentes de língua portuguesa do Ensino Fundamental - é essencial para que, inclusive, futuramente, tenhamos condições para repensar e reavaliar as disciplinas e conteúdos abordados no Profletras, a fim de aprimorar a formação de centenas de professores de língua portuguesa, de maneira sólida e robusta, tal como se espera em um Mestrado Profissional, ou seja, em um curso stricto sensu.

Além disso, acreditando que o melhor material didático que existe é um professor bem formado, procuramos demonstrar, nesse artigo, que investir na formação de professores de língua portuguesa é investir na qualidade de ensino de língua portuguesa e, para que isso ocorra de maneira satisfatória, é preciso que conheçamos, minimamente, esses professores e as crenças linguísticas que os constituem.

Em consonância com tais conviç̧̃̃es, apresentamos resultados de nossa investigação realizada sobre crenças de mestrandos do Profletras (professores da Educação Básica) da Universidade Federal de Uberlândia
(UFU) e da Universidade Federal do Triângulo Mineiro (UFTM- Uberaba). Com a aplicação do teste de crenças, além de traçarmos o perfil social do aluno do Profletras dessas universidades, pudemos evidenciar que tais professores, apesar de já apresentarem algumas concepções que vão além das tradicionalmente presentes nas aulas de língua portuguesa, afirmando, por exemplo, que não existe uma modalidade mais correta que a outra, ou então que a língua de um analfabeto não é "errada", percebemos que há, ainda, a presença de muitos mitos e conceituações equivocadas sobre a língua, como, por exemplo, a crença de que a escrita é "mais correta" que a fala.

0 teste nos revelou também que esses mesmos professores, em sua maioria, já sofreram algum tipo de discriminação devido à variedade linguística que falam. Tal dado, além de reforçar o fato de que o preconceito linguístico está presente em nossa sociedade, chama-nos à atenção para a importância de um ensino sociolinguístico de língua capaz de fazer das salas de aula, sobretudo nas aulas de língua portuguesa, um campo fértil de discussões a respeito do caráter heterogêneo e multifacetado da língua, contribuindo, assim, para o combate ao preconceito linguístico.

Cabe destacar que a aplicação do teste de crenças utilizado nessa pesquisa, também nos levou a outros questionamentos, tais como: i) qual a formação em Sociolinguística desses professores?; ii) qual a opinião deles sobre essa área?; iii) eles acreditam que a Sociolinguística pode contribuir para melhoria da qualidade do ensino de língua portuguesa?; iv) qual a opinião desses professores sobre a variedade linguística de seus alunos? Questionamentos estes que pretendemos responder em pesquisas futuras, a fim de aprimorar nossas investigações acerca das crenças linguísticas desse público específico.

Assim, partindo das reflexões e dos resultados obtidos nesta pesquisa, acreditamos ter contribuído para a defesa de um ensino de língua portuguesa 
amparado em uma pedagogia culturalmente sensível, com vistas à redução do abismo, muitas vezes existente, entre professores e alunos. Além disso, sob essa "nova" perspectiva de ensino de língua, enfatizamos que a escola deve se tornar um espaço onde o professor respeita a diversidade social e linguística do alunado, buscando desenvolver práticas efetivas e aderentes à sua realidade de sala de aula. Somente assim, poderemos oportunizar uma aprendizagem satisfatória a nossos alunos, habilitando-os, para além dos muros da escola, a monitorar e a adequar as diferentes variedades linguísticas às variadas práticas sociais.

\section{Referências}

ALKMIM, Tânia Maria. Sociolinguística (Parte I). In: MUSSALIM, Fernanda; BENTES, Anna Christina (Org.). Introdução à linguística: domínios e fronteiras. 2. ed. São Paulo: Cortez, 2001. Vol. 1, p. 21-47.

ALMEIDA BARONAS, Joyce Elaine. Variação Linguística na Escola: resultado de um Projeto. Revista da ABRALIN, v. 13, n. 1, p. 39-62, jan./jun. 2014.

BAGNO, Marcos. Nada na língua é por acaso: por uma pedagogia da variação linguística. São Paulo: Parábola, 2007.

O que é letramento? Letramento e gêneros textuais. In: BAGNO, Marcos, STUBBS, Michael; GAGNÉ, Gilles (Org.). Língua Materna: letramento, variação \& ensino. São Paulo: Parábola, 2002. p. 51-58.

BAKHTIN, Mikhail Mjkhailovitch. Os gêneros do discurso. Estética da criação verbal. Tradução de Maria Ermantina Galvão Pereira. 2. ed. São Paulo: Martins Fontes, 1997. p. 278-326.

BERNAL, Regina; SILVA, Nilza Nunes da. O uso do EXCEL para análises estatísticas: curso de bioestatística. São Paulo: USP, 2012.

BORTONI-RICARDO, Stela Maris; DETTONI, Rachel do Vale. Diversidades linguísticas e desigualdades sociais: aplicando a pedagogia culturalmente sensível. In: COX, Maria Inês; ASSIS PETERSON, Ana Antônia (Org.). Cenas de sala de aula. Campinas: Mercado das Letras, 2001. p. 81-103.
BRASIL. Ministério da Educação. Parâmetros Curriculares Nacionais (PCN): Língua Portuguesa. Brasília: MEC, 1997.

Ministério da Educação. Parâmetros Curriculares Nacionais (PCN): Língua Portuguesa. Brasília: MEC, 1998.

CAMACHO, Roberto Gomes. Sociolinguística (Parte II). In: MUSSALIM, Fernanda; BENTES, Anna Christina (Org.). Introdução à linguística: domínios e fronteiras. 2. ed. São Paulo: Cortez, 2001. Vol. 1, p. 49-76.

. A variação lingüística. In: Subsídios à proposta curricular de língua portuguesa para o $1^{\circ}$ e e $2^{o}$ graus. São Paulo: SE/CENP, 1988. Vol. 3.

CAVALCANTE, Ricardo Bezerra et al. Análise de conteúdo: considerações gerais, relações com a pergunta de pesquisa, possibilidades e limitações do método. In: Inf. \& Soc.: Est., v. 24 , n. 1 , p. $13-18$, jan./abr. 2014

CYRANKA, Lucia Furtado de Mendonça. Atitudes linguísticas de alunos de escolas públicas de Juíz de Fora-MG. 2007. 174 fl. Tese (Doutorado em Estudos Linguísticos) Instituto de Letras, Universidade Federal Fluminense, Niterói, 2007.

CYRANKA, Lucia Furtado de Mendonça; RONCARATI, Claudia. Crenças de professores e alunos de português de escolas públicas de Juiz de Fora-MG. In: RONCARATI, Claudia; ABRAÇADO, Jussara (Org.). Português brasileiro II: contato linguístico, heterogeneidade e história. Rio de Janeiro: FAPERJ/EDUFF, 2008. p. 172.

CYRANKA, Lucia Furtado de Mendonça. A pedagogia da variação linguística é possível? In: ZILLES, Ana Maria Sthal; FARACO, Carlos Alberto (Org.). Pedagogia da variação linguística. São Paulo: Parábola, 2015. p. 31-51.

ERICKSON, Frederick. Transformation and school success: the politics and culture of educational achievement. Anthropology \& Education Quaterly, New York, v. 18, n. 4, p. 335-356, 1987.

FARACO, Carlos Alberto. Norma Culta Brasileira: desatando alguns nós. São Paulo: Parábola Editorial, 2008.

. Por uma pedagogia da variação linguística. Disponível em: <https://variacao linguistica.files.wordpress.com/2011/06/faraco-_por_uma_pedagogia_da_variacao_ linguistica1.pdf>. Acesso em jan. 2017.

FREIRE, Paulo. Educação como prática de liberdade. São Paulo, 2011.

GNERRE, Maurice. Linguagem, escrita e poder. São Paulo: Martins Fontes, 1985. 
LABOV, Willian. Language in the inner city. Philadelphia: University of Pennsylvania Press, 1972.

MARCUSCHI, Luiz Antônio. Da fala para a escrita: atividades de retextualização. 8 ed. São Paulo: Cortez, 2007.

MARTINS, Marco Antonio; VIEIRA, Silvia Rodrigues; TAVARES, Maria Alice. Ensino de português e sociolinguística. São Paulo: Contexto, 2014.

MINAYO, Maria Cecília de Souza. O desafio do conhecimento: Pesquisa qualitativa em saúde. 10. ed. São Paulo: HUCITEC, 2007.

TRAVAGLIA, Luiz Carlos. Gramática e interação: uma proposta para o ensino de gramática no $1^{\text {o }}$ e $2^{\circ}$ graus. 2. ed. São Paulo: Cortez, 1997.

Recebido em 21/08/2016.

Aceito em 19/01/2017. 